\title{
BUCOLOME, A POTENT BINDING INHIBITOR FOR FUROSEMIDE, ALTERS THE PHARMACOKINETICS AND DIURETIC EFFECT OF FUROSEMIDE: POTENTIAL FOR USE OF BUCOLOME TO RESTORE DIURETIC RESPONSE IN NEPHROTIC SYNDROME
}

\author{
Norito Takamura, ${ }^{1}$ Toru Maruyama, Etsuo Chosa, Keiichi Kawai, Yasuhiro Tsutsumi, \\ Yukie Uryu, Keishi Yamasaki, Tsuneo Deguchi, and Masaki Otagiri
}

Department of Pharmacy, Miyazaki Medical College Hospital, Miyazaki, Japan (N.T., K.Y.); Department of Biopharmaceutics, Graduate School of Pharmaceutical Sciences, Kumamoto University, Kumamoto, Japan (T.M., Y.T., Y.U., T.D., M.O.); Department of Orthopedic Surgery, Miyazaki Medical College, Miyazaki, Japan (E.C.); and School of Health Sciences, Faculty of Medical Kanazawa University, Kanazawa, Japan (K.K.)

Received October 29, 2004; accepted January 4, 2005

\section{ABSTRACT:}

To determine whether bucolome (5-n-butyl-1-cyclohexyl-2,4,6-trioxoperhydropyrimidine), a nonsteroidal anti-inflammatory agent, can reverse diuretic resistance of furosemide in patients with nephrotic syndrome, we examined the inhibitory effect of bucolome on the protein binding of furosemide in serum and urine. Bucolome significantly inhibited the protein binding of furosemide not only in serum but also in urine of preparation albumin (UPA), which mimics urinary albumin concentration in patients with nephrotic syndrome by ultrafiltration method. The binding percentage of furosemide to albumin was approximately $70 \%$ in UPA. With coadministration of bucolome to healthy volunteers, renal clearance of furosemide was increased, reflecting the increase of the free fraction of furosemide in serum. Furthermore, coadministration of bucolome caused a significant increase of urine volume and sodium concentration in urine. Even at higher urine levels of furosemide, the inhibitory effect of bucolome on the protein binding of furosemide in UPA remains constant, and changes in $\mathrm{pH}$ at weakly acidic $\mathrm{pH}$ levels (pH 5.5-6.5) did not alter the inhibitory effect of bucolome. Interestingly, coadministration of bucolome with furosemide in doxorubicin (Adriamycin)-induced nephrotic syndrome model rats alleviated the diuretic resistance. These results suggest that bucolome has a potent inhibitory effect on the protein binding of furosemide in the urine and can partially restore the diuretic response of furosemide in patients with nephrotic syndrome by increasing the free fraction of furosemide at the site of action.
Attenuated response to diuretics is frequently observed in patients with nephrotic syndrome (Green and Mirkin, 1980; Keller et al., 1982; Smith et al., 1985; Kirchner et al., 1990, 1992; Wilcox, 2002). Dose-response analysis comparing urinary excretion rates of diuretic and sodium has demonstrated that nephrotic patients are less responsive to a given dose of drug than healthy subjects (Smith et al., 1985). It has been proposed that this blunted response is due to tubular resistance to the natriuretic effect of loop diuretics. Another possible contribution to diuretic resistance in patients with nephrotic syndrome is suggested by the finding that furosemide readily binds to albumin in serum (Takamura et al., 1996, 1997, 1998), which implies that it also binds to albumin in urine. Since the protein-bound fraction of a drug is considered to be inactive (Martin, 1965; Meyer and Guttman, 1968; Vallner, 1977), binding of furosemide to urinary albumin would decrease the effective drug concentration by reducing its unbound fraction at its site of action in the thick ascending limb of Henle's

\footnotetext{
${ }^{1}$ Current address: Second Department of Clinical Pharmacy, School of Pharmaceutical Sciences, Kyushu University of Health and Welfare, Yoshino, Nobeoka, Japan.

Article, publication date, and citation information can be found at http://dmd.aspetjournals.org.
}

doi:10.1124/dmd.104.002782. loop. This suggests that binding inhibitors for furosemide can normalize the natriuretic effect of the drug in renal tubules.

To have a significant renal effect, a protectable inhibitor should have the following properties: 1) it should be a potent inhibitor of the protein binding of furosemide in urine; 2) when administered in large doses, its plasma concentration should reach high levels; 3 ) it should be excreted mainly in urine; and 4) it should be highly safe and suitable for repeated administration.

Kirchner et al. (1991) reported that binding inhibitors such as warfarin and sulfisoxazole alleviated the blunted response to furosemide in rats in their in vivo loop microperfusion experiments. However, warfarin is eliminated by metabolism rather than urinary excretion, despite it has high affinity for albumin (Kragh-Hansen, 1981; Maes et al., 1982). In addition, warfarin can only be administered in small doses. Some sulfa drugs, including sulfisoxazole and sulfamethizole, are eliminated mainly by urinary excretion but have low affinity for albumin (binding affinity, $\mathrm{n} K=1 \times 10^{4} \mathrm{M}^{-1}$ to $5 \times$ $10^{4} \mathrm{M}^{-1}$ ) (Vallner, 1977; Kragh-Hansen, 1981), suggesting that these drugs would not be effective in restoring the blunted response to furosemide in patients with nephrotic syndrome (Agarwal et al., 2000).

Previously, we reported that furosemide binds to site I on human

ABBREVIATIONS: HSA, human serum albumin; UPA, urine of preparation albumin; RSA, rat serum albumin; NS rat, nephrotic syndrome model rat; HPLC, high-performance liquid chromatography; $\mathrm{CL}_{\text {tot }}$, total body clearance; $\mathrm{CL}_{r}$, renal clearance; $\mathrm{AUC}$, area under the $\mathrm{Curve}$ 
serum albumin (HSA), which is one of the major binding sites for drugs on HSA. Also, we found that valproic acid, phenytoin, and bucolome inhibited binding of furosemide to HSA (Takamura et al., 1996). Bucolome, a nonsteroidal anti-inflammatory drug, can be administered in large doses (600-1200 mg/day); its plasma concentration reaches about $300 \mu \mathrm{M}$, and it is excreted mainly in urine (Kakemi et al., 1970; Yashiki et al., 1971a,b; Chiba et al., 1985).

In the present study, we investigated the effects of bucolome on the pharmacokinetics and pharmacodynamics of furosemide in healthy subjects and doxorubicin (Adriamycin)-induced nephrotic syndrome model rats. First, we studied the effects of bucolome on protein binding of furosemide in serum and urine, and found that bucolome is an effective binding inhibitor for furosemide. Moreover, we found that coadministration of bucolome affects the pharmacokinetics of furosemide, based on the inhibition of protein binding, suggesting an increased natriuretic effect of the diuretic. These results suggest that bucolome can alleviate diuretic resistance in patients with nephrotic syndrome.

\section{Materials and Methods}

Materials. Furosemide powder and furosemide intravenous solution (20 $\mathrm{mg} / \mathrm{ml}$ ) were donated by Hoechst Japan Co. (Tokyo, Japan). Adriamycin was donated by Kyowa Hakko Kogyo Co. (Tokyo, Japan). HSA (essentially fatty acid-free) and rat serum albumin (RSA) were purchased from Sigma-Aldrich (St. Louis, MO). RSA was defatted with activated charcoal in solution at $0^{\circ} \mathrm{C}$, acidified with $\mathrm{H}_{2} \mathrm{SO}_{4}$ to $\mathrm{pH} 3$, and then freeze-dried (Tsutsumi et al., 1999). Bucolome (5- $n$-butyl-1-cyclohexyl-2,4,6-trioxoperhydropyrimidine; Grelan Pharmaceutical Co. Ltd., Tokyo, Japan) was obtained as a pure substance from the manufacturer. All other chemicals were of analytical grade.

Protein Binding Study. Ultrafiltration experiments were performed using a Tosoh plastic ultrafiltration apparatus (Tosoh, Kanagawa, Japan). Aliquots (0.9 or $1.35 \mathrm{ml}$ ) of different concentrations of furosemide and a constant concentration of HSA (in $63 \mathrm{mM}$ sodium phosphate buffer, $\mathrm{pH}$ 7.4), serum protein, RSA, or urine of preparation albumin (UPA), which mimics urinary albumin concentration observed in patients with nephrotic syndrome by adding the HSA to urine of healthy volunteers, were centrifuged at 1200 or $2200 \mathrm{~g}$ for 15 min at $25^{\circ} \mathrm{C}$. Adsorption of drugs onto the membrane or apparatus was negligible. No protein leakage was detected during the experiment.

The free concentrations of furosemide and bucolome were determined by HPLC using a system consisting of a Shimadzu LC-6A UV detector (Shimadzu, Kyoto, Japan) and a Shimadzu SPD-6A pump. For both drugs, a Superspher 100 RP-18e column (Cica Merck, Tokyo, Japan) was used as the stationary phase. Both furosemide (retention time, $4.3 \mathrm{~min}$ ) and bucolome (retention time, $5.3 \mathrm{~min}$ ) were assayed by UV monitoring at $280 \mathrm{~nm}$. HPLC was performed at a flow rate of $1.0 \mathrm{ml} / \mathrm{min}$ at $40^{\circ} \mathrm{C}$ with a column oven, using distilled water/acetonitrile/methanol (491:9:4 v/v), and distilled water/ acetonitrile $(119: 6 \mathrm{v} / \mathrm{v})$ as the mobile phase for furosemide and bucolome, respectively.

Effect of Bucolome on the Natriuretic Effect of Furosemide in Healthy Volunteers. The protocol was approved in advance by the Ethical Committee of Miyazaki College Hospital. A family member of the volunteer was asked to give informed consent when the volunteer was unable to do so, according to Japanese legislation. The subjects were three normal male humans, 34 to 48 years old and weighing 65 to $79 \mathrm{~kg}$, who participated as outpatients. Each subject had a normal medical history, physical condition, and standard laboratory test results. Intake of sodium and fluid was maintained at constant levels in all experiments. It has been reported that the $t_{\max }$ of bucolome is $4.5 \mathrm{~h} \mathrm{in}$ humans (Yashiki et al., 1971b). To obtain the maximum displacement effect by bucolome for the protein biding of furosemide, each subject was intravenously administered $20 \mathrm{mg}$ of furosemide, alone or $4.5 \mathrm{~h}$ after pretreatment with bucolome (600 mg p.o.). An interval of at least 2 weeks elapsed between experiments (crossover fashion). Blood samples $(6 \mathrm{ml})$ used to determine drug concentrations were obtained $5,10,15,30,60,120$, and $240 \mathrm{~min}$ after administration of furosemide. The blood was immediately centrifuged at 3000 $\mathrm{rpm}$ for $10 \mathrm{~min}$, and the serum was stored at $-80^{\circ} \mathrm{C}$ until analysis for furosemide. In separate experiments, free furosemide concentration in humans was determined by ultrafiltration techniques.

The concentration of furosemide in serum was determined using the HPLC system described above. An Inertsil ODS column (5 $\mu \mathrm{m}$ ) (GL Sciences Inc., Tokyo, Japan) was used as the stationary phase. A $0.2-\mu \mathrm{g}$ aliquot containing the internal standard, ethyl $p$-hydroxybenzoate, was added to $0.1-\mathrm{ml}$ serum samples. This mixture was vortexed, followed by addition of $0.5 \mathrm{ml}$ of $1 \mathrm{M}$ potassium dihydrogenphosphate and $3 \mathrm{ml}$ of diethyl ether. The mixture was shaken for $10 \mathrm{~min}$ and then centrifuged $(3000 \mathrm{rpm}$ ) for $10 \mathrm{~min}$. The upper layer $(2 \mathrm{ml})$ was transferred to a clean test tube and evaporated under nitrogen to dryness. Then, $250 \mu \mathrm{l}$ of mobile phase was added to the tube, and the resultant mixture was injected into the HPLC apparatus. HPLC was performed at a flow rate of $1.1 \mathrm{ml} / \mathrm{min}$ at $40^{\circ} \mathrm{C}$ with a column oven, using $50 \mathrm{mM}$ potassium dihydrogenphosphate/acetonitrile $(68: 32 \mathrm{v} / \mathrm{v})$ as the mobile phase for furosemide (retention time, $8.0 \mathrm{~min}$ ). A UV monitor was used to assay for furosemide and ethyl $p$-hydroxybenzoate, at a UV wavelength of $270 \mathrm{~nm}$ for both.

Analysis of In Vitro Binding of Furosemide. Binding parameters were estimated by fitting the experimental data to the following equation using a nonlinear least-squares computer program (MULTI) (Yamaoka et al., 1981):

$$
r=\frac{\left[D_{\mathrm{b}}\right]}{\left[P_{\mathrm{t}}\right]}=\sum_{\mathrm{i}=1}^{\mathrm{j}} \frac{n_{\mathrm{i}} K_{\mathrm{i}}\left[D_{\mathrm{f}}\right]}{1+K_{\mathrm{i}}\left[D_{\mathrm{f}}\right]}
$$

where $r$ is the number of moles of bound drug per protein molecule, $\left[D_{\mathrm{b}}\right]$ and $\left[D_{\mathrm{f}}\right]$ are the bound and unbound drug concentrations, $\left[P_{\mathrm{t}}\right]$ is the total protein concentration, and $K_{\mathrm{i}}$ and $n_{\mathrm{i}}$ are the binding constant and the number of binding sites, respectively, for the class of binding sites. The simultaneous binding of two ligands was analyzed using a previously reported method (Kragh-Hansen, 1981), as follows:

$$
\begin{aligned}
& r_{\mathrm{A}}=\frac{\left[A_{\mathrm{b}}\right]}{\left[P_{\mathrm{t}}\right]}=\frac{K_{\mathrm{A}}\left[A_{\mathrm{f}}\right]+\chi K_{\mathrm{BA}} K_{\mathrm{B}}\left[A_{\mathrm{f}}\right]\left[B_{\mathrm{f}}\right]}{1+K_{\mathrm{A}}\left[A_{\mathrm{f}}\right]+K_{\mathrm{B}}\left[B_{\mathrm{f}}\right]+\chi K_{\mathrm{BA}} K_{\mathrm{B}}\left[A_{\mathrm{f}}\right]\left[B_{\mathrm{f}}\right]} \\
& r_{\mathrm{B}}=\frac{\left[B_{\mathrm{b}}\right]}{\left[P_{\mathrm{t}}\right]}=\frac{K_{\mathrm{B}}\left[B_{\mathrm{f}}\right]+\chi K_{\mathrm{AB}} K_{\mathrm{A}}\left[A_{\mathrm{f}}\right]\left[B_{\mathrm{f}}\right]}{1+K_{\mathrm{A}}\left[A_{\mathrm{f}}\right]+K_{\mathrm{B}}\left[B_{\mathrm{f}}\right]+\chi K_{\mathrm{BA}} K_{\mathrm{B}}\left[A_{\mathrm{f}}\right]\left[B_{\mathrm{f}}\right]}
\end{aligned}
$$

where $K_{\mathrm{A}}$ and $K_{\mathrm{B}}$ are the binding constants of ligands $\mathrm{A}$ and $\mathrm{B},\left[A_{\mathrm{f}}\right]$ and $\left[B_{\mathrm{f}}\right]$ are the free concentrations of ligands $\mathrm{A}$ and $\mathrm{B}$, and $\left[A_{\mathrm{b}}\right]$ and $\left[B_{\mathrm{b}}\right]$ are the bound concentrations of ligands A and B. $\chi$ is a coupling constant, $K_{\mathrm{BA}}$ is the binding constant of ligand $\mathrm{A}$ in the presence of ligand $\mathrm{B}$, and $K_{\mathrm{AB}}$ is the binding constant of ligand $\mathrm{B}$ in the presence of ligand $\mathrm{A}$. Using these equations, we calculated the theoretical values of $\chi$. The interaction mode of the ligands on a macromolecule can be evaluated from the sign and magnitude of the value of $\chi$. For example, if ligands $\mathrm{A}$ and $\mathrm{B}$ are independently bound to protein, $\chi$ is equal to 1 . The results $\chi>1$ and $0<\chi<1$ indicate cooperative and anti-cooperative interaction between ligands. Competitive displacement between ligands is indicated by $\chi=0$. In this analysis, $r<0.42$ was used to suppress the contribution of a low-affinity binding site.

Inhibition of furosemide binding by bucolome was estimated from monitored changes of the free ligand fraction, $f_{\mathrm{u}}$, which was calculated as follows:

$$
f_{\mathrm{u}}=\frac{\left[D_{\mathrm{f}}\right]}{\left[D_{\mathrm{f}}\right]+\left[D_{\mathrm{b}}\right]}
$$

Pharmacokinetics of Furosemide in Normal and Nephrotic Syndrome Model Rats. Adult male Wistar rats were housed in an air-conditioned room with free access to commercial feed and water, and fasted for $16 \mathrm{~h}$ before the abdominal aorta injection. All animal experiments were conducted according to the guideline principle and procedures of Kumamoto University for the care and use of laboratory animals. Experimental nephrotic syndrome was induced in rats by administration of Adriamycin in a single injection $(7.5 \mathrm{mg} / \mathrm{kg}$ ) via the tail vein (referred to as nephrotic syndrome model rats, or NS rats) (Bertani et al., 1982). Control rats were injected with isotonic saline. Male Wistar rats (250-290 g; 2 weeks after i.v. administration of Adriamycin or saline) underwent the surgical procedure under light anesthesia with diethyl ether. A cannula was inserted into the femoral vein and artery, using polyethylene tubing (polyethylene-50; i.d., $0.58 \mathrm{~mm}$; o.d., $0.9655 \mathrm{~mm}$; BD Biosciences, San 
(A)

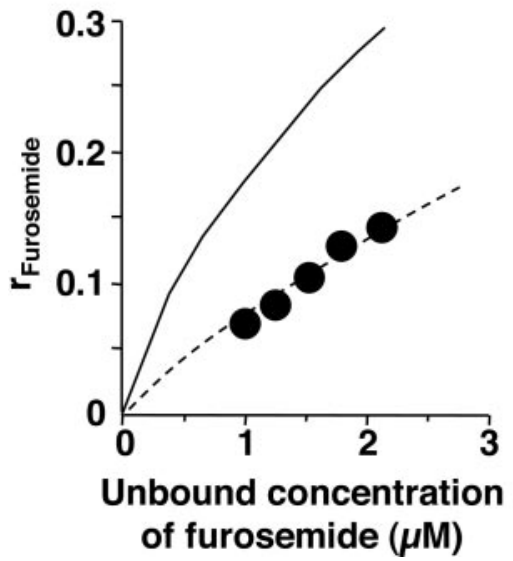

(B)

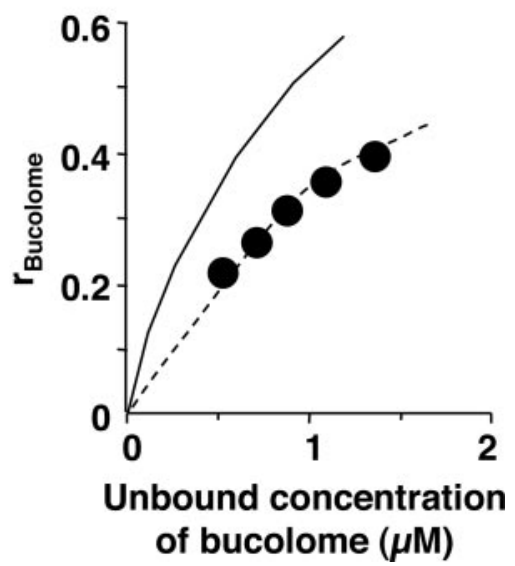

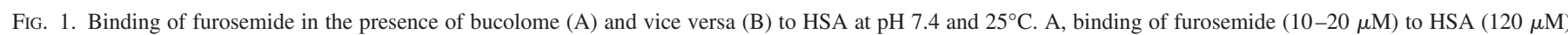

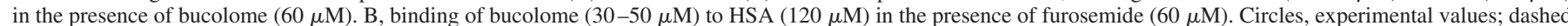

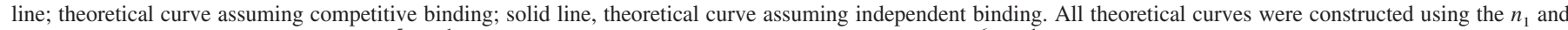
$K_{1}$ values [furosemide, $n_{1} \cdot K_{1}=2 \times 10^{5} \mathrm{M}^{-1}$ (Takamura et al., 1996); bucolome, $n_{1} \cdot \mathrm{K}_{1}=1.5 \times 10^{6} \mathrm{M}^{-1}$ ].

Jose, CA). The bladder was also cannulated with polyethylene tubing (polyethylene-8; o.d., $2.33 \mathrm{~mm}$; Hibiki Co., Tokyo, Japan.). The body temperature of the rats was maintained by heating with a lamp. Thirty minutes before the i.v. injection of furosemide, control samples of urine were collected. Furosemide was administered at a dose of $2 \mathrm{mg} / \mathrm{kg}$ by rapid infusion into the femoral vein, alone or $1 \mathrm{~h}$ after oral pretreatment with bucolome considering the pharmacokinetics of bucolome $\left(t_{\max }\right.$ of bucolome in rats $=53.5 \mathrm{~min}$, data not shown). After infusion, the cannulae were flushed with a small volume of heparinized saline, to ensure that the complete dose was administered and to prevent the formation of clots. Blood samples $(200 \mu \mathrm{l})$ and urine were taken from the femoral artery and bladder, respectively, at designated times. The blood was placed in graduated microcentrifuge tubes $(0.6 \mathrm{ml})$ that contained a drop of heparinized saline as an anticoagulant. The blood samples were centrifuged ( $1500 \mathrm{~g}$ for $10 \mathrm{~min})$, and the plasma was removed.

Plasma concentration profiles were analyzed by fitting the following biexponential equation with the nonlinear least-squares method (MULTI):

$$
C_{\mathrm{p}}=\mathrm{A} \cdot \exp (-\alpha \cdot t)+\mathrm{B} \cdot \exp (-\beta \cdot t)
$$

Pharmacokinetic parameters were calculated using the following equations:

$$
\begin{gathered}
\mathrm{AUC}_{0 \rightarrow \infty}=\mathrm{A} / \alpha+\mathrm{B} / \beta \\
\mathrm{CL}_{\mathrm{tot}}=\text { Dose } / \mathrm{AUC} \\
t_{1 / 2 \beta}=0.693 / \beta
\end{gathered}
$$

where $\mathrm{AUC}_{0-\infty}, \mathrm{CL}_{\mathrm{tot}}$, and $t_{1 / 2 \beta}$ represent $\mathrm{AUC}$ from zero to infinity, total body clearance, and half-life of the $\beta$ phase, respectively.

Statistical Analysis. Student's $t$ test was used to analyze differences between two groups. Analysis of variance was used to analyze differences among more than two groups, and the significance of difference between two means in these groups was evaluated using the modified Fisher's least-squares difference method.

\section{Results}

Effect of Bucolome on the Protein Binding of furosemide In Vitro. To estimate the effect of bucolome on the protein binding of furosemide, we have measured the free fraction of furosemide in human serum in the absence and presence of bucolome. Protein binding of furosemide $(20 \mu \mathrm{M})$ was significantly inhibited by $300 \mu \mathrm{M}$ bucolome, and $f_{\mathrm{u}}$ of furosemide in the presence of bucolome $\left(f_{\mathrm{u}}=\right.$ $3.00 \pm 0.12 \%$ ) was approximately 3 -fold greater than the value in the absence of bucolome $\left(f_{\mathrm{u}}=1.10 \pm 0.09 \%\right)$.

Figure 1 shows the results of a quantitative analysis of mutual displacement between furosemide and bucolome. The kinetic binding constant $\left(n_{1} \cdot K_{1}\right)$ of furosemide on the binding to HSA was reported to be $2.0 \times 10^{5} \mathrm{M}^{-1}$ (Takamura et al., 1996), and that of bucolome was determined to be $1.5 \times 10^{6} \mathrm{M}^{-1}$ (data not shown). Taking their parameters into consideration, a $60 \mu \mathrm{M}$ concentration of these ligands will inhibit the binding to albumin. In this condition, the binding isotherm of furosemide in the presence of bucolome, and vice versa, was fairly close to the theoretical curve that assumed competition between these two ligands at a common site.

Effect of Bucolome on the Pharmacokinetics of Furosemide in Healthy Volunteers. Table 1 summarizes the pharmacokinetic parameters of furosemide after intravenous administration $(20 \mathrm{mg})$ with and without oral coadministration of bucolome $(600 \mathrm{mg})$ in healthy volunteers. In the group with coadministration of bucolome, AUC decreased significantly, and $\mathrm{CL}_{\mathrm{tot}}$, renal clearance $\left(\mathrm{CL}_{\mathrm{r}}\right)$, and steady-state volume of distribution $\left(V_{\mathrm{dss}}\right)$ increased significantly. However, $t_{1 / 2 \beta}$ was unchanged. These results suggest that the alteration of pharmacokinetics of furosemide was caused by inhibition of protein binding by bucolome. In fact, at 5, 10, and $15 \mathrm{~min}$ after administration of furosemide, the free fraction of furosemide increased significantly in the group with coadministration of bucolome (Fig. 2).

Effect of Bucolome on the Natriuretic Effect of Furosemide in Healthy Volunteers. To evaluate the pharmacodynamics of furosemide, urine volume and sodium concentration in urine were measured at $6 \mathrm{~h}$ after intravenous administration of furosemide. As mentioned above, in the group with coadministration of bucolome, renal clearance of furosemide was increased (Table 1). This result is consistent with the significant increase of urine volume and sodium concentration in urine (Table 2).

Effect of Bucolome on the Protein Binding of Furosemide in Urine. To restore the diuretic response in patients with nephrotic syndrome, a binding inhibitor (bucolome) must displace the diuretic (furosemide) in urine containing a high concentration of albumin. To determine whether bucolome inhibits the protein binding of furosemide in urine, ultrafiltration was performed using artificial nephrotic urine, which contains a level of albumin equivalent to that of patients with nephrotic syndrome. The results indicate that bucolome inhibited the protein binding of furosemide in the artificial nephrotic urine (Fig. 3A). This inhibition was not affected by changes in the $\mathrm{pH}$ of urine that simulated the acidosis that occurs in nephrotic syndrome (Fig. 3B). 
TABLE 1

Kinetic parameters of furosemide after single intravenous injection of furosemide to healthy volunteers alone $(A)$ and with bucolome $(B)$

Each value represents the mean \pm S.D. $(n=3)$.

\begin{tabular}{lll}
\hline & $\begin{array}{c}\text { Furosemide } \\
\text { Alone }\end{array}$ & With Bucolome \\
\hline $\mathrm{AUC}(\mathrm{mg} / \mathrm{l} \cdot \mathrm{h})$ & $2.55 \pm 0.22$ & $1.84 \pm 0.24^{* * *}$ \\
$\mathrm{CL}_{\mathrm{tot}}(\mathrm{l} / \mathrm{h})$ & $7.89 \pm 0.60$ & $11.0 \pm 1.35^{*}$ \\
$\mathrm{CL}_{\mathrm{r}}(\mathrm{l} / \mathrm{h})$ & $3.63 \pm 0.57$ & $8.37 \pm 1.43^{* *}$ \\
$V_{\mathrm{dss}}(\mathrm{liters})$ & $5.54 \pm 0.96$ & $8.57 \pm 1.11^{* *}$ \\
$t_{1 / 2 \beta(\mathrm{h})}$ & $0.67 \pm 0.28$ & $0.69 \pm 0.26$ \\
\hline
\end{tabular}

$* p<0.05 ; * * p<0.01 ; * * * p<0.001$ vs. furosemide alone.

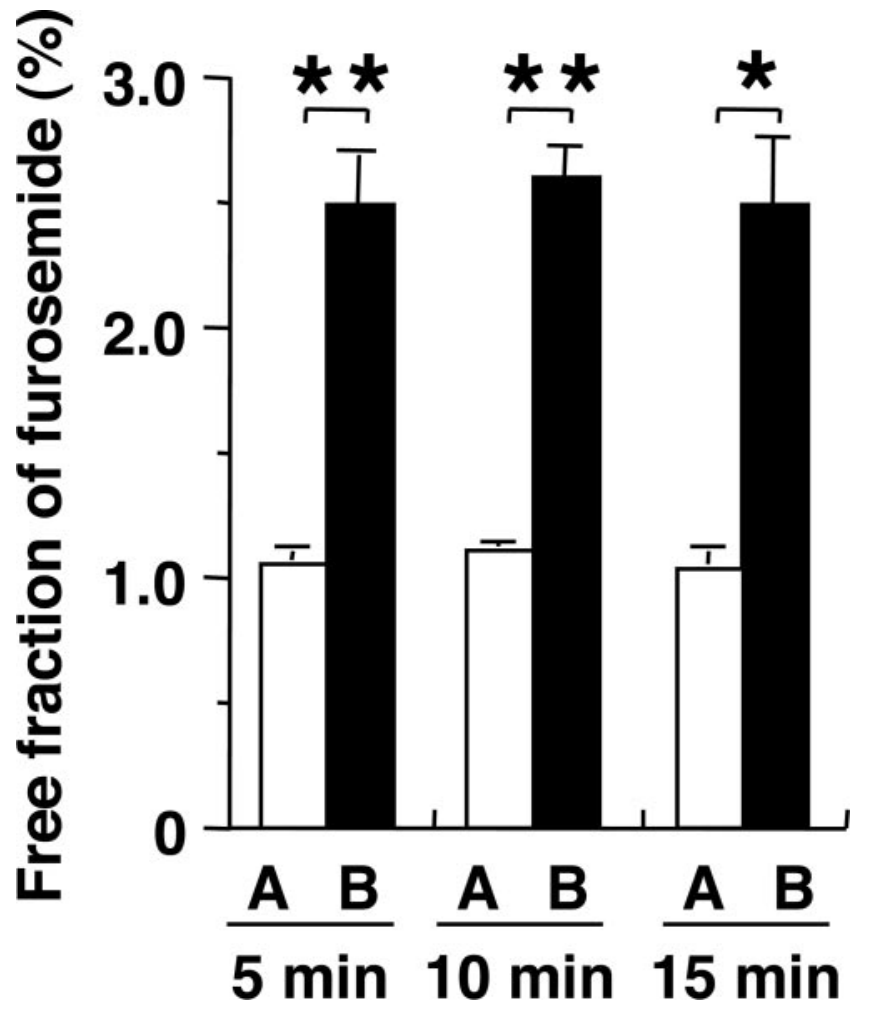

FIG. 2. Serum protein binding of furosemide after single intravenous injection of furosemide to healthy volunteers, alone (A) and with bucolome (B). The serum-free fraction of furosemide was determined at 5, 10, and 15 min after single intravenous administration. Each column is the mean of three experiments \pm S.D. $\star, p<0.05$ (A versus B); $\star \star, p<0.01$ (A versus B). Statistical analysis was performed by paired $t$ test.

TABLE 2

Urine volume and urinary excretion of sodium for $6 \mathrm{~h}$ after single intravenous injection of furosemide to healthy volunteers alone $(A)$ and with bucolome $(B)$ Each value represents the mean \pm S.D. $(n=3)$.

\begin{tabular}{lcl}
\hline & Furosemide Alone & With Bucolome \\
\hline Urine volume (liters) & $1.23 \pm 0.15$ & $1.48 \pm 0.12^{*}$ \\
Urinary sodium $(\mathrm{mM})$ & $7.89 \pm 0.60$ & $11.0 \pm 1.35^{*}$ \\
\hline
\end{tabular}

$* p<0.05$ vs. furosemide alone.

Effect of Bucolome on the Pharmacokinetics of Furosemide in Normal Rats. Table 3 summarizes the pharmacokinetic parameters of furosemide after intravenous administration $(2 \mathrm{mg} / \mathrm{kg}$ ) with and without oral coadministration of bucolome in normal rats. An increase in the dose of bucolome caused a significant decrease of AUC, and a significant increase of $\mathrm{CL}_{\mathrm{tot}}, \mathrm{CL}_{\mathrm{r}}, V_{\mathrm{dss}}$, and $f_{\mathrm{u}}$

To confirm whether furosemide and bucolome share the same binding site on RSA, we studied the interaction between furosemide and bucolome. In vitro binding analysis indicated that bucolome inhibited the binding of furosemide competitively (data not shown). Furosemide and bucolome have approximately the same affinity for RSA (furosemide, $K_{\mathrm{a}}=4.30 \times 10^{6} \pm 0.64 \times 10^{6} \mathrm{M}^{-1}$; bucolome, $K_{\mathrm{a}}$ $=6.63 \times 10^{6} \pm 1.79 \times 10^{6} \mathrm{M}^{-1}$ ). The affinity of furosemide for RSA was greater than its affinity for HSA [primary binding affinity $K_{1}=2 \times 10^{5} \mathrm{M}^{-1}$ (Takamura et al., 1996)], whereas bucolome had approximately equal affinity for RSA and HSA $\left(K_{1}=1.5 \times 10^{6}\right.$ $\mathrm{M}^{-1}$ ). The strong agreement between these findings and the pharmacokinetics and binding mode of furosemide in human and rats suggests that the present NS rats constitute a relevant model for analysis of interaction between furosemide and bucolome.

Effect of Bucolome on the Diuretic Effect of Furosemide in Normal and NS Rats. Adriamycin-treated rats exhibited symptoms of nephrotic syndrome. In NS rats, serum albumin was significantly decreased, and urinary albumin was markedly increased (Table 4). Body weight was significantly decreased in NS rats, and hematocrit and urine volume tended to be lower in NS rats than in normal rats.

To evaluate the effect of bucolome on diuretic resistance in NS rats, urine volume and furosemide excretion into urine were measured. Urine volume increased with increasing dose of bucolome, which is consistent with the significant increase of urinary excretion of furosemide in normal rats (Fig. 4, A and C). Although NS rats exhibited attenuation of diuretic response, compared with normal rats (Fig. 4, C and D), diuretic resistance was restored by oral coadministration of bucolome, accompanied by an increase of urinary excretion of furosemide (Fig. 4, B and D).

\section{Discussion}

Attenuated diuretic response is frequently observed in cases of chronic administration of furosemide (Green and Mirkin, 1980; Keller et al., 1982; Smith et al., 1985; Kirchner et al., 1990, 1992; Wilcox, 2002). It is thought that a possible cause of this attenuation is a decrease of circulating blood volume and glomerular filtration rate, which leads to a decrease in the concentration of sodium ions in the thick ascending limb of Henle's loop and a compensating increase of sodium reabsorption in the distal tubule (Loon et al., 1989). However, in nephrotic syndrome, because a great amount of albumin is present in urine, furosemide may bind to albumin rather than to the $\mathrm{Na}^{+}-\mathrm{K}^{+}$$2 \mathrm{Cl}^{-}$cotransporter, decreasing its effectiveness (Green and Mirkin, 1980; Keller et al., 1982; Smith et al., 1985; Kirchner et al., 1990, 1992; Wilcox, 2002). This suggests that diuretic resistance can be restored by effective inhibition of furosemide-albumin binding, which should cause an increase of the free concentration of furosemide in renal tubules. The binding inhibitor should possess the following properties: 1) it is a potent inhibitor of the protein binding of furosemide in urine; 2) when administered in large doses, its plasma concentration reaches high levels; 3 ) it is primarily excreted in urine; and 4) it is highly safe and suitable for prolonged administration. In a previous study, we demonstrated that valproic acid, phenytoin, and bucolome, which all bind to site I, inhibited the protein binding of furosemide when administered at typical clinical doses (Takamura et al., 1996). Bucolome, a nonsteroidal anti-inflammatory drug, is usually administered in large doses (600-1200 mg); its plasma concentration is typically about $300 \mu \mathrm{M}$, and it is primarily eliminated by urine excretion (Kakemi et al., 1970; Yashiki et al., 1971a,b; Chiba et al., 1985). It has been reported that bucolome does not affect urinary enzyme activities, suggesting that any nephrotoxicity of bucolome would be very low-level (Tsurumi et al., 1978). Also, bucolome has been used to treat nephrotic syndrome patients in warfarin-bucolome combination therapy (Sato et al., 1991). Thus, it appears that buco- 
(A)
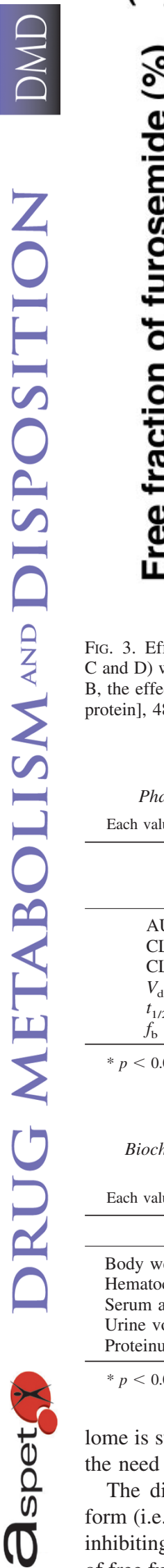

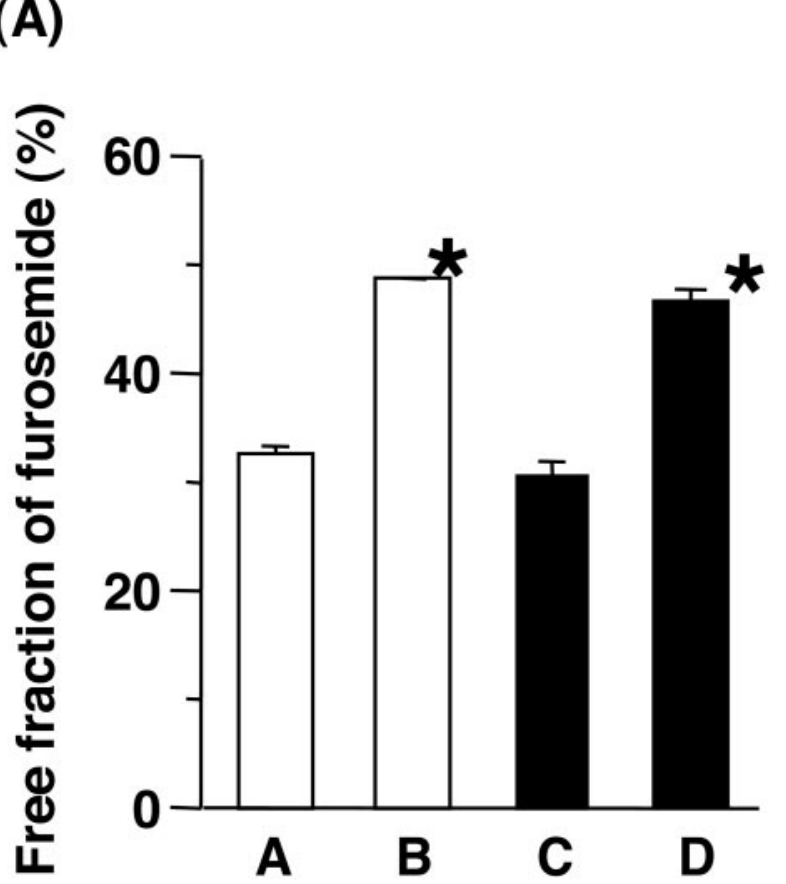

(B)

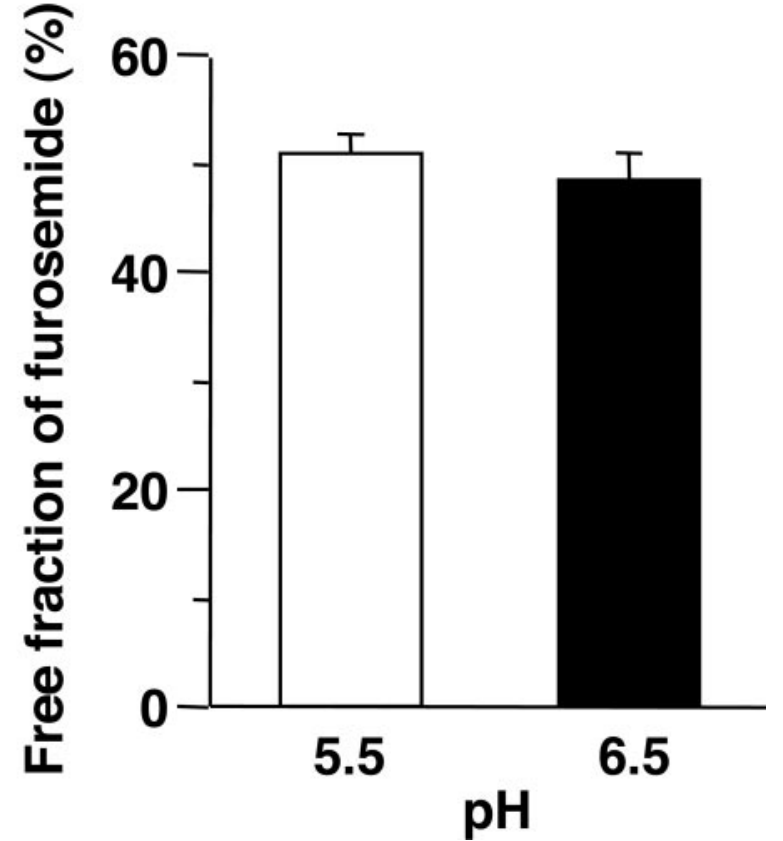

FIG. 3. Effect of bucolome on the protein binding of furosemide in UPA. A, concentration-dependent protein binding of furosemide ( $30 \mu \mathrm{M}$, bars A and B; $60 \mu \mathrm{M}$, bars $\mathrm{C}$ and $\mathrm{D}$ ) was examined without bucolome (bars A and C) and with $500 \mu \mathrm{M}$ bucolome (bars B and D) at $25^{\circ} \mathrm{C}$. Concentration of urinary protein was $480 \mu \mathrm{M}$ (as HSA). $\mathrm{B}$, the effect of $\mathrm{pH}$ on the protein binding of furosemide was examined in the presence of bucolome in UPA at $25^{\circ} \mathrm{C}$. The following concentrations were used: [urinary protein], $480 \mu \mathrm{M}$ (as HSA); [furosemide], $30 \mu \mathrm{M}$; [bucolome], $500 \mu \mathrm{M}$. Each bar represents mean \pm S.D. $(n=3) \star \star, p<0.001$ versus furosemide alone.

TABLE 3

Pharmacokinetic parameters of furosemide after single intravenous injection to normal rats $(2 \mathrm{mg} / \mathrm{kg})$ alone and with oral coadministration of bucolome Each value represents the mean \pm S.D. $(n=3-4)$.

\begin{tabular}{lcccc}
\hline \multirow{2}{*}{ Parameter } & Furosemide & \multicolumn{3}{c}{ With Bucolome } \\
\cline { 3 - 4 } & Alone & $10 \mathrm{mg} / \mathrm{kg}$ & $15 \mathrm{mg} / \mathrm{kg}$ & $20 \mathrm{mg} / \mathrm{kg}$ \\
\hline $\mathrm{AUC}(\mu \mathrm{g} / \mathrm{ml} \cdot \mathrm{min})$ & $563 \pm 82$ & $572 \pm 31$ & $414 \pm 47^{*}$ & $336 \pm 91^{* *}$ \\
$\mathrm{CL}$ & $3.61 \pm 0.52$ & $3.51 \pm 0.19$ & $4.87 \pm 0.52$ & $6.24 \pm 1.54 *$ \\
$\mathrm{CL}_{\mathrm{tot}}(\mathrm{ml} / \mathrm{min} / \mathrm{mg})$ & $1.08 \pm 0.16$ & $1.42 \pm 0.25$ & $2.11 \pm 0.24^{* *}$ & $2.67 \pm 0.42^{* *}$ \\
$V_{\mathrm{dss}}(\mathrm{ml} / \mathrm{kg})$ & $75.7 \pm 6.0$ & $75.1 \pm 1.3$ & $92.1 \pm 5.6 *$ & $112 \pm 7 * *$ \\
$t_{1 / 2 \beta}(\mathrm{min})$ & $44.7 \pm 12.7$ & $33.6 \pm 3.7$ & $35.7 \pm 9.6$ & $29.4 \pm 4.5$ \\
$f_{\mathrm{b}}(\%)$ & $1.28 \pm 0.36$ & $1.41 \pm 0.72$ & $1.99 \pm 0.76$ & $3.03 \pm 0.57 * *$ \\
\hline
\end{tabular}

$* p<0.05 ; * * p<0.01$ vs. furosemide alone.

\section{TABLE 4}

Biochemical parameters at 2 weeks after intravenous administration of Adriamycin $(9 \mathrm{mg} / \mathrm{kg})$

Each value represents the mean \pm S.D. $(n=3-6)$.

\begin{tabular}{lcc}
\hline & Control & With Adriamycin \\
\hline Body weight $(\mathrm{g})$ & $203 \pm 11$ & $176 \pm 16^{*}$ \\
Hematocrit $(\%)$ & $37.4 \pm 3.9$ & $35.4 \pm 1.7$ \\
Serum albumin level $(\mathrm{ml} / \mathrm{min} / \mathrm{kg})$ & $3.75 \pm 0.14$ & $3.03 \pm 0.23^{* *}$ \\
Urine volume (ml/day) & $6.53 \pm 0.47$ & $6.27 \pm 3.00$ \\
Proteinuria (mg/day) & $9.04 \pm 4.15$ & $275 \pm 84^{*}$ \\
\hline
\end{tabular}

$* p<0.05 ; * * p<0.01$ vs. control.

lome is suitable for treatment of nephrotic syndrome patients, despite the need for careful monitoring of renal function.

The diuretic resistance caused by decreased levels of the active form (i.e., unbound form) of furosemide in urine can be alleviated by inhibiting protein binding of furosemide, which increases the amount of free furosemide delivered to the site of action. In the present study, when bucolome was administered with furosemide in healthy volun- teers, the free fraction of furosemide in plasma increased (Fig. 2), as predicted by the in vitro data (Fig. 1). The free fractions of some ligands were slightly influenced by the temperature (Melten et al., 1986), suggesting that the present protein binding obtained by ultrafiltration at $25^{\circ} \mathrm{C}$ might be greater than that at $37^{\circ} \mathrm{C}$. However, in terms of the qualitative analysis, it is suggested that bucolome inhibits the binding of furosemide under in vivo physiological conditions. Therefore, a decrease in the AUC and an increase in the $\mathrm{CL}_{\text {tot }}$ and $V_{\mathrm{dss}}$ would be due to the decrease in the protein binding of furosemide (Table 1). Also, the natriuretic effect of furosemide was reinforced by coadministration of bucolome (Table 2). We hypothesize that the alterations of these pharmacokinetic parameters were caused by the increase in the amount of furosemide available for the hepatic metabolism and renal excretion, followed by the increase in the free fraction of furosemide. The increase of renal clearance of furosemide resulted in the increase of the amount reaching the site of action (Table 1), the $\mathrm{Na}^{+}-\mathrm{K}^{+}-2 \mathrm{Cl}^{-}$cotransporter and induced the acceleration of the diuretic effect (Table 2).

Even though the amount of furosemide reaching the site of action 
(A)

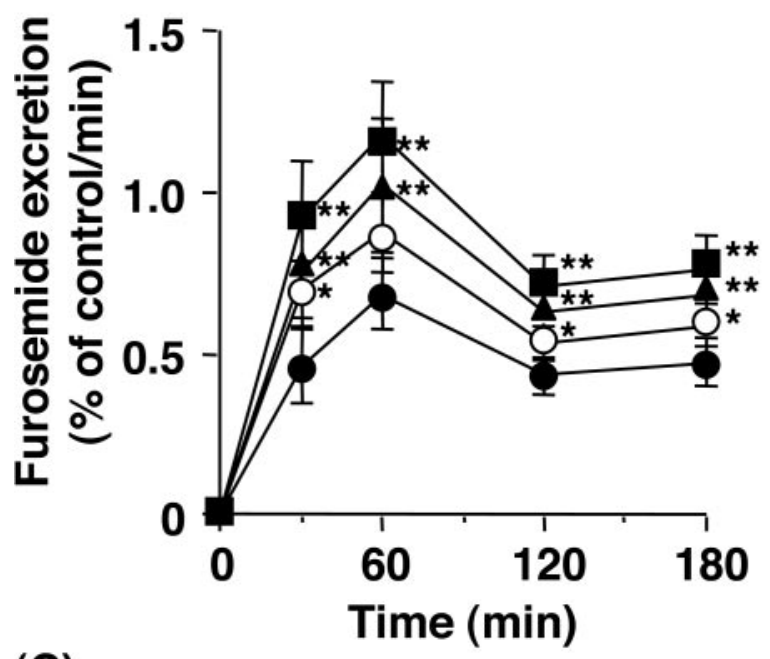

(C)

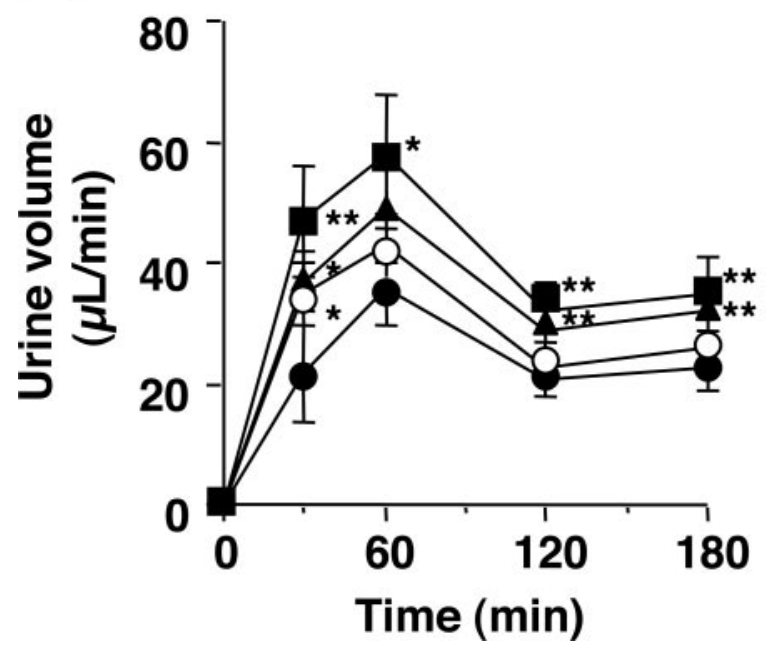

(B)

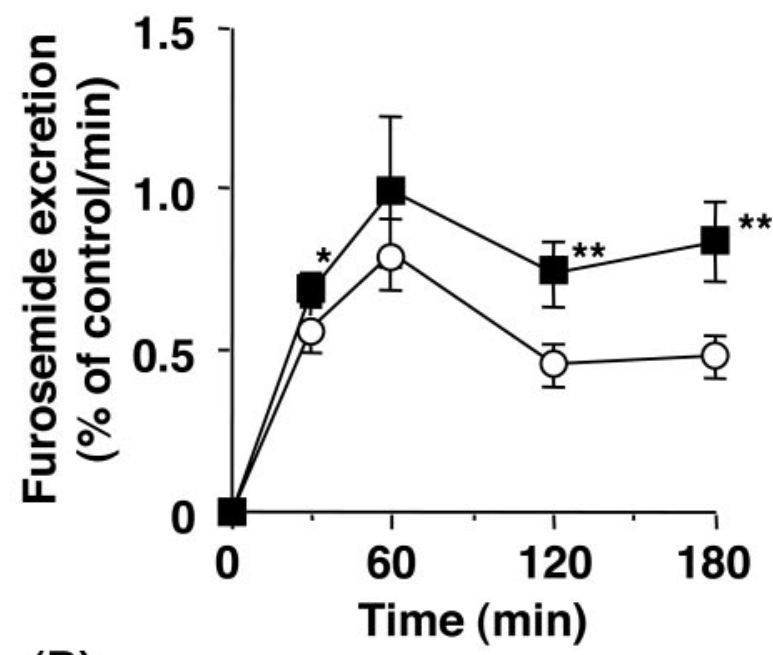

(D)

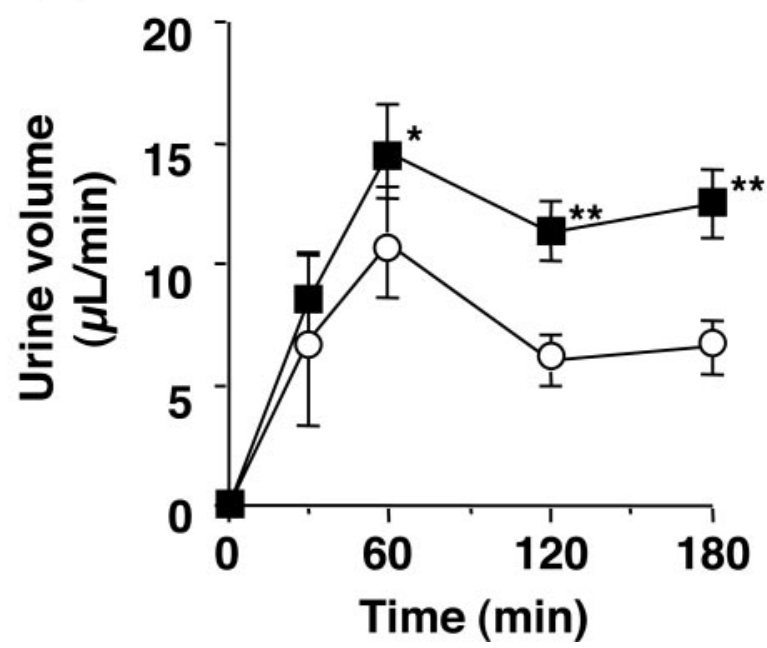

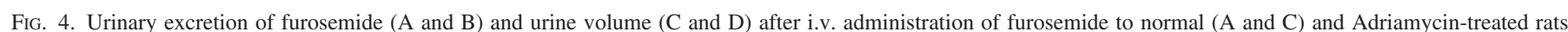

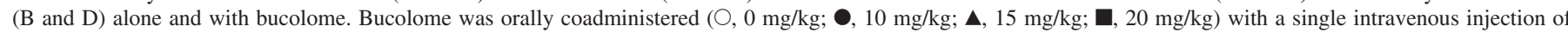

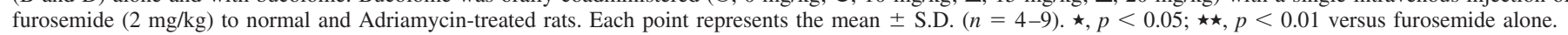

was increased by the coadministration of bucolome, unless the protein binding of furosemide in urine is inhibited, the blunted response to furosemide may not be alleviated in patients with nephrotic syndrome. In the present study, accurate concentrations of drugs tested in the nephrotic loop could not be estimated. However, considering the pharmacokinetic parameters of furosemide (Table 1) and bucolome (Yashiki et al., 1971a,b), their urinary concentrations were expected to reach about 30 and $500 \mu \mathrm{M}$, respectively. Additionally, the clinical dose of furosemide is often increased in patients with nephrotic syndrome. Therefore, we assumed that urinary concentrations of furosemide and bucolome in the renal tubules were 30 or $60 \mu \mathrm{M}$, and $500 \mu \mathrm{M}$, respectively (Fig. 3A), although they would be more concentrated than the artificial urine used in this experiment. As a result, we demonstrated that bucolome effectively inhibited the protein binding of furosemide, even in urine. Sulfamethizole and sulfisoxazole, which bind to site I of HSA, did not inhibit the protein binding of furosemide in urine, even at doses of $1 \mathrm{mM}$, although they inhibit binding effectively in plasma (data not shown). This suggests that it is important for the binding inhibitor to possess the high affinity for albumin exhibited by bucolome $\left(n_{1} \cdot K_{1}=1.5 \times 10^{6} \mathrm{M}^{-1}\right)$. In addition, as an inhibitor for protein binding of furosemide in urine, bucolome has the advantage that its effects are not altered by changes in $\mathrm{pH}$ (Fig. 3B) or the presence of other drugs, including sulfamethizole and sulfisoxazole. The binding percentage of furosemide in artificial urine was about $70 \%$ (Fig. 3A), which was lower than the percentage in plasma (about 99\%), suggesting that alteration of $\mathrm{pH}$ between urine and plasma, and/or endogenous inhibitors, such as fatty acid, uremic toxins, and eicosanoids, may be involved in the protein binding of furosemide in the urine (Kragh-Hansen et al., 2002).

Interestingly, we found that coadministration of bucolome with furosemide in Adriamycin-induced NS rats alleviated the diuretic resistance (Fig. 4). It has been repeatedly shown that the urinary concentration of loop diuretic is the best index of drug concentration at the intraluminal site of action in the thick ascending limb of Henle's loop. Also, there are publications for furosemide that depict urine output versus excretion rates to better reflect the pharmacodynamics (Green and Mirkin, 1980; Keller et al., 1982; Smith et al., 1985; Kirchner et al., 1990, 1992; Wilcox, 2002). In the present study, promotion of diuretic effects by bucolome was accompanied by an increasing urinary excretion rate of furosemide (Fig. 4), suggesting an increase in the amount of furosemide delivered to the site of action. These results are in good agreement with the present findings for 
healthy subjects, suggesting that this therapeutic strategy can restore the diuretic response to furosemide in patients with nephrotic syndrome. The affinity of furosemide for RSA was higher than its affinity for HSA, although bucolome had approximately equal affinity for RSA and HSA. The inhibitory effect of bucolome on the protein binding of furosemide in plasma and urine is likely to be stronger in humans than rats, suggesting that bucolome has a greater effect on the diuretic properties of furosemide in patients with nephrotic syndrome than in NS rats. On the other hand, the mean urine volume attained by the coadministration of bucolome $(20 \mathrm{mg} / \mathrm{kg})$ with furosemide in the NS rats (Fig. 4D, 395-753 $\mu \mathrm{l}$ ) was still less than that observed in normal rats (Fig. 4C, 1352-2103 $\mu \mathrm{l}$ ), although coadministration of bucolome with furosemide doubled the urinary excretion of furosemide at $3 \mathrm{~h}$ postdose (Fig. 4, A and B). Thus, the present limited data suggested that coadministration of bucolome with furosemide may partially restore the diuretic resistance in the nephrotic rats. A critical element of the present strategy is to increase the amount of free furosemide delivered to the site of action. In the condition of repeated administration, that is, the clinically relevant situation, high concentrations of furosemide and bucolome would be maintained in the urine. Therefore, the inhibitory effect of bucolome by chronic dosing may be more possibly generated compared with that by single dosing.

The present results suggest that coadministration of bucolome can partially reverse the diuretic resistance of furosemide in patients with nephrotic syndrome. These findings may lead to an effective clinical therapy for alleviation of diuretic resistance of furosemide in nephrotic syndrome.

\section{References}

Agarwal R, Gorski JC, Sundblad K, and Brater DC (2000) Urinary protein binding does not affect response to furosemide in patients with nephrotic syndrome. J Am Soc Nephrol 11:1100-1105.

Bertani T, Poggi A, Pozzoni R, Delaini F, Sacchi G, Thoua Y, Mecca G, Remuzzi G, and Donati MB (1982) Adriamycin-induced nephrotic syndrome in rats: sequence of pathologic events. Lab Investig 46:16-23.

Chiba K, Yoshida M, Ishihara A, Sudo J, Tanabe T, Miyazaki S, and Takada M (1985) Study of interactions between ibuprofen and sulfonamides and between bucolome and sulfonamides in rats. Chem Pharm Bull (Tokyo) 33:3415-3421.

Green TP and Mirkin BL (1980) Resistance of proteinuric rats to furosemide: urinary drug protein binding as a determinant of drug effect. Life Sci 26:623-630.

Kakemi K, Sezaki H, Komuro T, Ikeda K, and Kishi H (1970) Effect of 5-n-butyl-1-cyclohexyl2,4,6-trioxoperhydropyrimidine on the sulfonamides transfer in the rat. Chem Pharm Bull (Tokyo) 18:2386-2392.

Keller E, Hoppe-Seyler G, and Schollmeyer P (1982) Disposition and diuretic effect of furosemide in the nephrotic syndrome. Clin Pharmacol Ther 32:442-449.

Kirchner KA, Voelker JR, and Brater DC (1990) Intratubular albumin blunts the response to furosemide—a mechanism for diuretic resistance in the nephrotic syndrome. J Pharmacol Exp Ther 252:1097-1101.

Kirchner KA, Voelker JR, and Brater DC (1991) Binding inhibitors restore furosemide potency in tubule fluid containing albumin. Kidney Int 40:418-424.

Kirchner KA, Voelker JR, and Brater DC (1992) Tubular resistance to furosemide contributes to the attenuated diuretic response in nephrotic rats. J Am Soc Nephrol 2:1201-1207.

Kragh-Hansen U (1981) Molecular aspects of ligand binding to serum albumin. Pharmacol Rev 33:17-53.

Kragh-Hansen U, Chuang VT, and Otagiri M (2002) Practical aspects of the ligand-binding and enzymatic properties of human serum albumin. Biol Pharm Bull 25:695-704.

Loon NR, Wilcox CS, and Unwin RJ (1989) Mechanism of impaired natriuretic response to furosemide during prolonged therapy. Kidney Int 36:682-689.

Maes V, Engelborghs Y, Hoebeke J, Maras Y, and Vercruysse A (1982) Fluorimetric analysis of the binding of warfarin to human serum albumin. Equilibrium and kinetic study. Mo Pharmacol 21:100-107.

Martin BK (1965) Potential effect of the plasma on drug distribution. Nature (Lond) 207:274276.

Melten JW, Wittebrood AJ, Wemer J, and Faber DB (1986) On the modulating effects of temperature, albumin, $\mathrm{pH}$ and calcium on the free fractions of phenobarbitone and phenytoin. J Pharm Pharmacol 38:643-646.

Meyer MC and Guttman DE (1968) The binding of drugs by plasma proteins. J Pharm Sci $\mathbf{5 7 : 8 9 5 - 9 1 8 . ~}$

Sato H, Tawaraya H, Takagi A, Wakabayashi M, Yoshida K, Ueno M, Maruyama Y, Suzuki S, and Arakawa M (1991) [A case of heterozygous protein C deficiency associated with nephrotic syndrome and deep femoral artery thrombosis]. Nippon Jinzo Gakkai Shi 33:327-332.

Smith DE, Hyneck ML, Berardi RR, and Port FK (1985) Urinary protein binding, kinetics and dynamics of furosemide in nephrotic patients. J Pharm Sci 74:603-607.

Takamura N, Haruta A, Kodama H, Tsuruoka M, Yamasaki K, Suenaga A, and Otagiri M (1996) Mode of interaction of loop diuretics with human serum albumin and characterization of binding site. Pharm Res (NY) 13:1015-1019.

Takamura N, Maruyama T, and Otagiri M (1997) Effects of uremic toxins and fatty acids on serum protein binding of furosemide: possible mechanism of the binding defect in uremia. Clin Chem 43:2274-2280.

Takamura N, Shinozawa S, Maruyama T, Suenaga A, and Otagiri M (1998) Effects of fatty acids on serum binding between furosemide and valproic acid. Biol Pharm Bull 21:174-176.

Tsurumi K, Abe A, Nozaki M, and Fujimura H (1978) Influence of some anti-inflammatory, antipyretic and analgesic agents on urinary enzyme level in rats. J Toxicol Sci 3:1-9.

Tsutsumi Y, Maruyama T, Takadate A, Goto M, Matsunaga H, and Otagiri M (1999) Interaction between two dicarboxylate endogenous substances, bilirubin and an uremic toxin, 3-carboxy4-methyl-5-propyl-2-furanpropanoic acid, on human serum albumin. Pharm Res (NY) 16:916923.

Vallner JJ (1977) Binding of drugs by albumin and plasma protein. J Pharm Sci 66:447-465.

Wilcox CS (2002) New insights into diuretic use in patients with chronic renal disease. J Am Soc Nephrol 13:798-805.

Yamaoka K, Tanigawara Y, Nakagawa T, and Uno T (1981) A pharmacokinetic analysi program (MULTI) for microcomputer. J Pharmacobio-Dyn 4:879-885.

Yashiki T, Matsuzawa T, Yamada M, Kondo T and Mima H (1971a) Studies on the metabolic fate and the pharmacokinetics of 5-n-butyl-1-cyclohexyl-2,4,6-trioxoperhydropyrimidine $(\mathrm{BCP})$ in man. V. Pharmacokinetics of BCP in man and in rabbit following intravenous administration of BCPNa. Chem Pharm Bull (Tokyo) 19:881-891.

Yashiki T, Matsuzawa T, Yamada M, Kondo T, and Uda Y (1971b) Studies on the metabolic fate and the pharmacokinetics of 5-n-butyl-1-cyclohexyl-2,4,6-trioxoperhydropyrimidine (BCP) in man. IV. Pharmacokinetics of BCP in man following oral administration. Chem Pharm Bull (Tokyo) 19:869-880

Address correspondence to: Professor Masaki Otagiri, Department of Biopharmaceutics, Graduate School of Pharmaceutical Sciences, Kumamoto University, 5-1 Oe-honmachi, Kumamoto 862-0973, Japan. E-mail: otagirim@gpo. kumamoto-u.ac.jp 